\title{
Price risk exposure of Australian merinos - is it in the bloodline?
}

\author{
by Behrendt, $\mathrm{K}$.
}

Copyright, Publisher and Additional Information: This is the author accepted manuscript. The final published version (version of record) is available online via Csiro Publishing Please refer to any applicable terms of use of the publisher.

DOI: https://doi.org/10.1071/AN14305

\section{Harper Adams University}




\section{Price risk exposure of Australian merinos - is it in the bloodline?}

2 Karl Behrendt ${ }^{\mathrm{AB}}$

3 A Graham Centre for Agricultural Innovation (Charles Sturt University and NSW Department of Primary Industries), Charles

4 Sturt University, School of Agricultural and Wine Science, Orange, NSW 2800, Australia.

$5 \quad$ BAuthor for correspondence: email: kbehrendt@,csu.edu.au

6 Abstract

8 sheep breeding objectives and ram selection. To adequately assess the economic outcomes from different

9 bloodlines in the decision making process, there is a need to consider the impact of wool and sheep meat

10 price risk. Using a steady state wether flock model that accounts for the lifetime productivity of 268

11 reported Merino bloodlines and stochastic dependency in weekly wool and sheep meat prices from

12 28/6/2005 to 10/11/2011, Gross Incomes per Dry Sheep Equivalent (GI/DSE) were calculated for a

13 weekly time step. The analysis found that across all bloodlines and market price scenarios, GI/ DSE

14 ranged between $\$ 13.92$ and $\$ 67.83$, with an overall mean of $\$ 32.60$. The individual means of bloodlines

15 across the time series ranged from $\$ 37.46$ to $\$ 25.19 \mathrm{GI} / \mathrm{DSE}$. The coefficient of variation, used as the

16 measure of relative risk for each bloodline, ranged from 0.24 to 0.30 with a mean of 0.25 . The analysis

17 showed that a bloodlines exposure to price risk has a curvilinear relationship to fibre diameter and fleece

18 weight. The results from a risk-reward point of view indicate that the majority of Australian Merino

19 bloodlines are risk-inefficient. This suggests Australian sheep producers have a significant opportunity to

20 increase net returns and reduce price risk exposure by identifying and switching to more risk-efficient

21 bloodlines.

22 Keywords

23 Wool and sheep meat price risk, sheep bloodline productivity and economics, simulation, risk-

24 efficiency. 
Introduction

A key aspect in managing and developing profitable merino bloodlines is the need to give consideration to the uncertainty in the price and quantity of outputs (meat and wool) (Counsell and Vizard 1997). In-field sheep productivity trial data are commonly used to compare bloodline performance in decision making by sheep producers and their advisors (Butler 2006), with significant differences being reported in the profitability of different bloodlines (Coelli et al. 1996; Coelli and Atkins 2000; Martin et al. 2010). The economic ranking of different bloodlines has been shown to vary in response to different deterministic wool market price scenarios applied (Martin et al. 2010). Atkins and Coelli (1997) investigated the effect of price risk over 14 sale quarters and reported that price risk only produced significant gross margin variations for bloodlines with a wool fibre diameter of less than 20.5 microns. While the majority of studies into bloodline performance have incorporated some uncertainty regarding productivity estimates, the issue of price uncertainty has largely been overlooked and any decision regarding bloodline selection should consider the balance between average returns and variability (Atkins and Coelli 1997).

To fully assess the likely economic performance of a bloodline requires the incorporation of price risk and predicted life-time bloodline performance. Given the increasing contribution of sheep meat

41 income to enterprise profitability in Australian merino based production systems (Curtis 2009), there is 42 also a need to incorporate sheep meat price risk into the analysis of bloodline performance.

The economic literature relating to risk in agricultural production systems, is generally based on

44 expected utility theory (Hardaker et al. 2004). This method assumes that a decision maker aims to maximise their expected utility, and requires some knowledge of the decision maker's personal utility function (Anderson et al. 1977). The practical difficulties in establishing such a utility function are 47 substantial (Hershey et al. 1982), and various efforts have been made to avoid the need for such a 48 function (Hardaker et al. 2004). Antle (1983), for example, argues that dynamic risk neutral models, are 49 more useful in defining the effects of risk in agricultural systems, allowing the decision maker to identify 50 preferable strategies a posteriori. 
The phenotypic diversity of merino bloodlines in the Australian merino flock and the associated

52

53

54

55

56

57

58

59

60

61

62

uncertainty of sheep meat and wool prices are significant components when selecting an appropriate bloodline from a set of risky alternatives. To analyse these risky alternatives, without the need to specify a decision maker's utility function, an alternative method based on efficiency analysis (Hardaker et al. 2004) that integrates wool and sheep meat price risk to estimate a risk-efficient frontier (Cacho et al. 1999) for Australian merino bloodlines is developed. Application of this method will assist decision makers with the identification of a risk-efficient set of bloodlines and thus allow the producer to decide where on the frontier they would like to operate so as to correspond to their current level of risk aversion.

\section{Methodology}

Based on a steady state economic model of bloodline performance, this study utilised aggregated results from in-field sheep bloodline production trials (Martin et al. 2010), to simulate the effects of stochastic wool and sheep meat prices on bloodline profitability.

To account for possible stochastic dependency between price variables (sheep meat and wool), simulations were completed through the use of a historical data set that describes concurrent wool, mutton and merino weaner prices. This method of dealing with stochastic dependency between price variables assumes that the historical data is representative of the future (Hardaker et al. 2004). The data set used represented weekly prices over the period of 28/6/2005 to 10/11/2011. Weekly mutton and merino weaner price data is derived from NSW saleyard indicators (MLA various issues), with the wool micron price guides derived from national wool micron indicators (AWEX various issues).

\section{Bloodline economic model}

The key economic measure of bloodline performance used in this analysis is the gross income per Dry Sheep Equivalent (DSE) generated in a wether enterprise operating under a steady state. In a steady state system, total numbers are maintained at a constant after sales, purchases and mortalities have been accounted for. Gross Income per DSE at time period $t, G I_{t}$, is calculated as;

$$
G I_{t}=\frac{T I+\sum_{n=1}^{3} W I_{n}}{s c}
$$


where $n$ is an index for age, $T I$ is the total trading income per hectare (ha) for a bloodline, $W I_{n}$ is

the total wool income/ha for age cohort $n$, and $s c$ is the assumed stocking capacity in DSE/ha. The value of trading income, TI, is a function of the number of animals being sold and purchased, their weight and their market value, under a steady state system:

$$
T I=P_{N} B W T_{1} \beta_{D P W} W N R P_{t}+S_{N} B W T_{n} \beta_{D P M} M P_{t}
$$

where $P_{N}$ and $S_{N}$ are the number of animals purchased and sold under a steady state condition, $B W T_{1}$ and $B W T_{n}$ are the liveweights of animals purchased and sold, $\beta_{D P W}$ and $\beta_{D P M}$ are the dressing percentages for merino weaners and wethers, and $W N R P_{t}$ and $M P_{t}$ are the market values for merino weaners and mutton in $\$ / \mathrm{kg}$ dressed weight at time period $t$. Prior to incorporation into the bloodline economic model, the trait data reported in Martin, Atkins et al. (2010) are transformed into absolute numbers for each bloodline using reported deviations and trait means (Table 1).

\section{Insert Table 1Table $\mathbb{1}$ near here}

The body weight of each particular age cohort is determined from the derived body weight of a bloodline, which is taken as the Standard Reference Weight (SRW) of a bloodline and is assumed to correspond to the 3 year old cohort, and is then adjusted for expected maturity. In this analysis we assume $B W T_{1}=0.7 S R W$, which, in turn, assumes purchased merino weaners have been uninhibited in growth to the point of purchase. The number of animals purchased or sold under a steady state system, $P_{N}$ and $S_{N}$, are calculated as follows:

$$
P_{N}=\frac{s r}{1+(1-\gamma)+(1-\gamma)^{2}+\cdots+(1-\gamma)^{n-1}} \text { and } S_{N}=P_{N}(1-\gamma)^{n-1}
$$

where $s r$ is the stocking rate in head/ha, and $\gamma$ is the mortality rate across all age groups. The stocking rate, sr, for each bloodline was standardised for their DSE rating which is determined by their relative metabolic size (Freer et al. 2007).

$$
s r=\frac{50^{0.75} S C}{S R W^{0.75}}
$$


Total wool income for a bloodline is the sum of the calculated wool income from each age cohort.

100 The calculated wool income for each age cohort, $W I_{n}$, is a function of the quantity of wool expected to be 101 grown, its fibre diameter and the wool price at time $t$. clean wool $/ \mathrm{hd}$, and $W P_{t}$ is the wool price in $\$ / \mathrm{kg}$ clean at time period $t$. In this analysis both the calculated

105 fleece weight and fibre diameter for each age cohort is adjusted for the derived annual change in fibre 106 diameter and clean fleece weight with age (Martin et al. 2010). The fleece weight for each age cohort is calculated from the derived clean fleece weight of a bloodline, $C F W$, which is assumed to correspond to the production from the 3 year old cohort. This is then adjusted for a bloodlines clean fleece weight stability measure, CFWST. Mathematically this is represented as: clip basis for 17 to 26 micron wool over the analysed period. To calculate non-whole point micron prices,

$113 M P G_{F D}$, a cubic spline was used to interpolate between whole point micron price guides, as well as 114 extrapolate outside of the whole point micron price guides. Such that,

$$
W P_{t}=M P G_{F D} C B_{F D}
$$
where $C B_{F D}$ is the predicted clip basis estimated for different clip fibre diameters from data

117 published by Counsell (2002), and allows for the reduction in average clip value due to the lower value of 118 oddments such as pieces, bellies, locks, stain and other miscellaneous wool found in a typical clip.

$$
C B_{F D}=-0.0054 F D_{n}{ }^{2}+0.2705 F D_{n}-2.4083
$$

where $F D_{n}$ is the fibre diameter in microns of age cohort $n$. The fibre diameter for each age cohort is calculated from the derived fibre diameter of a bloodline, which is taken as the Mean Fibre 123 adjusted for the bloodlines fibre diameter stability measure, FDST. Mathematically, this is represented as: 


$$
F D_{n}=M F D+F D S T(n-3) .
$$

The bloodline economic model is implemented and solved using Matlab (Mathworks_Inc 2013).

126 The simulation involves the analysis of 268 Merino bloodlines reported in Martin, Atkins et al. (2010), 127 and the use of 477 historical price scenarios for concurrent mutton, merino weaner and wool prices that 128 occurred over the period of 28/6/2005 to 10/11/2011. During this period the 19 micron premium ranged 129 between $4.2 \%$ and $36.6 \%$ and averaged $15.6 \%$, whereas the 21 micron premium ranged between $0.3 \%$ 130 and $10.1 \%$ with an average of $3.5 \%$. Table 2 provides summary statistics for the sheep meat and wool 131 prices used in this analysis. The included correlation matrix indicates positive correlations between 132 mutton and merino weaner prices over the period used in this analysis. Positive correlations also exist 133 between wool prices and sheep meat prices, indicating the need to account for stochastic dependency 134 between the price variables used in the analysis.

Insert Table 2 near here

136 Results

Analysis of the mean Gross Income per DSE for each bloodline and its variation, measured as the 138 standard deviation and coefficient of variation of Gross Income per DSE, indicates that bloodlines vary in 139 their risk-efficiency (Figure $1 \mathbf{a} \& \mathbf{b}$ ). Across all bloodlines and market price scenarios, income per DSE 140 ranged between $\$ 13.92$ and $\$ 67.83$ per DSE, with an overall average of $\$ 32.60$ per DSE. The mean 141 income per DSE for bloodlines ranged from $\$ 37.46$ to $\$ 25.19$ with a mean of $\$ 32.56$. The standard 142 deviation for mean income per DSE for bloodlines ranged from $\$ 9.50$ to $\$ 7.03$ and averaged $\$ 8.20$. The 143 data presented in Figure 1a indicates that a frontier to the risk-efficiency of bloodlines exists when 144 measured in absolute terms (grey line which links all risk-efficient bloodlines), where standard deviation 145 is used as the proxy for risk. Risk-efficient bloodlines are those that are not dominated by other bloodlines 146 in terms of maximising their profit and minimising their measure of risk. Table 3 indicates the mean 147 production characteristics of the risk-efficient set of bloodlines for different levels of risk aversion in 148 sheep producers. The identified risk-efficient bloodlines were evenly grouped into high, moderate and 149 low risk aversion sets. The low risk aversion set of bloodlines maximise returns regardless of the absolute 
variation in returns (found furthest to the right on the frontier), whereas the high risk aversion set of

151 bloodlines are found furthest to the left along the frontier and maximise returns while minimising risk.

\section{Insert Figure 1 near here}

\section{Insert Table 3 near here}

Results indicate that sheep producers with low risk aversion should choose bloodlines from the risk-efficient set that are finer in FD, heavier in CFW and lighter in BWT. Whereas sheep producers with high risk aversion should choose bloodlines from the risk-efficient set that are broader in FD, lighter in CFW and heavier in BWT. However, when risk is measured in relative terms as the coefficient of variation (cv) of returns (Figure 1b), two bloodlines are found to dominate all others (top left corner), as they achieve higher returns with less variation of returns. The results indicate that $\mathrm{cv}$ of returns ranged from 0.24 to 0.3 with a mean of 0.25 .

The key measures of bloodline productivity (being FD, CFW and BWT) indicate a curvilinear relationship with both mean bloodline returns and risk (Figure 2). The data indicates that FD has the strongest influence on both bloodline risks and returns, followed by CFW and BWT. There is a tendency for bloodline returns to increase with increasing fleece weights, however, the two most risk efficient bloodlines (based on relative risk) maintain slightly above average fleece weights, with both intermediate fibre diameter and body weights when compared to the available population.

\section{Insert Figure 2 near here}

\section{Discussion}

The method presented here allows sheep producers and their advisors to consider the risk profile of different bloodlines when making decisions regarding the future breeding direction of a flock. The application of the methodology to Australian merino bloodlines, in this instance, allowed the identification of risk-efficient bloodlines. Once risk-efficient sets of bloodlines are identified, sheep producers can select their optimal bloodline based on the profit they wish to generate and the risk they are willing to accept. This process allows sheep producers to trade off some risk for expected returns (Hardaker et al. 2004). It also allowed the production characteristics of those risk-efficient bloodlines to 
176 be indicated, which would enable producers with varying degrees of risk aversion to more easily identify 177 appropriate bloodlines for future purchase or breeding.

178 The results suggest that a bloodlines risk profile is linked to fibre diameter and fleece weight, and 179 to a lesser extent body weight. The curvilinear relationship that exists between fibre diameter and risk is 180 somewhat consistent with the findings of Atkins and Coelli (1997) who suggested that only finer

181 bloodlines had significant increases in their variability of returns. Although, this analysis did indicate that 182 risk is minimised when bloodlines have a fibre diameter around 20 microns. The results also indicate a 183 relationship between fleece weight and risk profile, with increasing fleece weight reducing the riskiness 184 of the bloodline, especially at lower fibre diameters. This finding is also consistent with Atkins and Coelli 185 (1997) who found that higher fleece weight bloodlines had lower coefficient of variations of gross margin 186 returns at the same fibre diameter. Although there is an indication that increasing fleece weight increases mean income, there is no 188 clear indication that fibre diameter or mature body weight influences Mean Income. However, the ranking 189 of bloodlines on a risk-efficiency basis is driven by the combination of productive factors driving 190 profitability. In particular, the effect of fleece weight in determining both mean income and variability of 191 returns, and fibre diameter in determining return variability through its expression of higher price 192 variability at lower fibre diameters (Table 2). Overall, the risk-reward profiles indicate that the majority 193 of Australian merino bloodlines are risk-inefficient (i.e. do not lie on the frontier or are dominated by 194 more profitable and/or less risky bloodlines) and sheep producers may either increase returns while 195 maintaining return variability or maintain returns and reduce return variability by switching to more risk196 efficient bloodlines.

197 Given the differences in bloodline risk-reward profiles when measured using standard deviation 198 as an absolute measure of risk, versus coefficient of variation as a relative measure of risk, the results 199 indicate that the mean return (i.e. mean gross income) is a greater determinant of risk-efficiency than 200 absolute risk. The results also indicate the need to balance between fleece weight and fibre diameter so as 
not to excessively increase the variability of returns when breeding objectives focus strongly on fibre diameter reduction in lieu of increasing or maintaining fleece weight.

This analysis does not consider all the traits and reported differences between bloodlines such as

204 fibre diameter cv, wool style, length, colour and staple strength (Casey et al. 2010). However Atkins and Coelli (1997) found that the additional measures of quality traits such as style, staple length, colour and tenderness contributed less than $1 \%$ to bloodline profitability. The importance of these measures in

207 defining wool prices changes overtime, so it would be expected that they may have an increasing 208 influence on bloodline profitability and may warrant inclusion in future analyses. In addition, with an increasing proportion of the Australian merino flock moving towards self-replacing systems with very few wethers making up the national flock structure (Curtis 2009), there is also a need to expand this analysis to consider the dynamics of ewe performance in assessing the risk-reward profile of bloodlines. The method applied to identify risk-efficient sets of bloodlines from which a decision maker

213 chooses, is limited by the assumption that the decision makers subjective probability distributions for

214 wool and sheep meat prices are identical to those historical prices used (Hardaker et al. 2004). This may

215 not always be the case in future markets. However, the methodology presented still provides an easily

216 applied method of identifying risk-efficient bloodlines from which sheep producers may choose

217 appropriate bloodlines for their level of risk aversion, if decision makers also define their expected future 218 wool and meat price variation as part of the analysis.

\section{Acknowledgements} providing access to Australian Merino Bloodline data and reviewing an early draft of this paper.

\section{References}

Anderson, JR, Dillon, JL, Hardaker, JB (1977) 'Agricultural decision analysis.' (Iowa State University Press:

Antle, JM (1983) Incorporating Risk in Production Analysis. American Journal of Agricultural Economics 65, 1099-1106. Atkins, KD, Coelli, KA (1997) Economic Evaluation of Merino Bloodlines including Risk Considerations. In 'Proceedings of the 12th Conference of the Association for the 
Advancement of Animal Breeding and Genetics. RSL Complex and Western Plains Zoo Dubbo NSW, Australia', 6th - 10th April 1997. Volume 12 pp. 701-704. (Association for the Advancement of Animal Breeding and Genetics. Available at http://agbu.une.edu.au/ aaabg/absfull.html - 148

AWEX, various issues. 1997 to 2009 Weekly MPG indicators. Australian Wool Exchange, Butler, L (2006) Ewe and wether trials - Tools for benchmarking your sheep genetics. Department of Agriculture and Food, Government of Western Australia.

Cacho, OJ, Bywater, AC, Dillon, JL (1999) Assessment of production risk in grazing models. Agricultural Systems 60, 87-98.

Casey, A, Martin, S, Graham, R, Semple, S, Atkins, KD (2010) Choosing a bloodline source. Industry \& Investment NSW.

Coelli, K, Atkins, K, Casey, A, Semple, S (1996) Genetic differences among Merino bloodlines from NSW and Victorian wether comparisons (1984-1995). International Journal of Sheep and Wool Science 44, 178-195.

Coelli, K, Atkins, KD (2000) This analysis of a Merino ewe enterprise supports the economic merit of fine wool bloodlines. Wool Technology and Sheep Breeding 48, 277-284.

Counsell, DJ (2002) Review of the sale performance of individual wool clips against regional Australian Wool Exchange micron price guides. Wool Technology and Sheep Breeding 50, 208-214.

Counsell, DJ, Vizard, AL (1997) Factors affecting the business risk of wool growing farms in the high rainfall zone of Australia. Wool Technology and Sheep Breeding 45, 256-266.

Curtis, K (2009) Recent changes in the Australian Sheep Industry. Department of Agriculture and Food WA, Perth.

Freer, M, Dove, H, Nolan, JV (Eds) (2007) 'Nutrient Requirements of Domesticated Ruminants.' In 'Feeding Standards for Australian Livestock: Ruminants'. (CSIRO Publishing: Collingwood)

Hardaker, JB, Huirne, RBM, Anderson, JR, Lien, G (2004) 'Coping with Risk in Agriculture.' (CABI Publishing: Wallingford)

Hershey, JC, Kunreuther, HC, Schoemaker, PJ (1982) Sources of bias in assessment procedures for utility functions. Management Science 28, 936-954.

Martin, S, Atkins, K, Semple, S, Sladek, M, Thackeray, R, Staines, J, Casey, A, Graham, R, Russell, A (2010) Merino Bloodlines: the comparison 1999-2010. Industry \& Investment NSW Available at http://www.dpi.nsw.gov.au/ data/assets/pdf file/0004/344920/merinobloodlines-the-comparisons-1999-2010.pdf.

Mathworks_Inc (Ed. TM Inc. (2013) 'R2013b (Version 8.2).' (The Mathworks Inc.: Massachusetts)

MLA, various issues. Meat \& Livestock Weekly. Meat \& Livestock Australia,

Tables \& Figures

Table 1: Summary of production characteristics for 268 Merino bloodlines (derived from Martin et al. (2010)). 


\begin{tabular}{lccccc}
\hline & $\begin{array}{c}\text { Fibre } \\
\text { Diameter } \\
\text { (um) }\end{array}$ & $\begin{array}{c}\text { Clean Fleece } \\
\text { Weight }(\mathrm{kg})\end{array}$ & $\begin{array}{c}\text { Body } \\
\text { Liveweight } \\
(\mathrm{kg})\end{array}$ & $\begin{array}{c}\text { Fibre } \\
\text { Diameter } \\
\text { Stability } \\
\text { (um/yr) }\end{array}$ & $\begin{array}{c}\text { Clean Fleece } \\
\text { Weight } \\
\text { Stability } \\
(\% / \mathrm{yr})\end{array}$ \\
\hline Mean & 19.59 & 4.18 & 51.2 & 0.48 & 5.17 \\
Standard Deviation & 1.03 & 0.24 & 2.06 & 0.32 & 2.14 \\
Maximum & 22.04 & 4.77 & 57.0 & 1.43 & 13.97 \\
Minimum & 16.74 & 3.41 & 47.1 & -0.80 & -2.94 \\
\hline
\end{tabular}

Table 2: Summary of historical wool and sheep meat price data from $28 / 6 / 2005$ to 10/11/2011

274 (Sources: (AWEX various issues; MLA various issues)). Price statistics are in cents/kg carcass weight for 275 merino weaners and mutton prices, and cents/kg clean for micron price guides.

\begin{tabular}{|c|c|c|c|c|c|c|c|c|}
\hline \multirow[t]{2}{*}{ Correlation Matrix } & \multicolumn{2}{|c|}{ Sheep meat } & \multicolumn{6}{|c|}{ Wool Fibre Diameter and Micron Price Guides } \\
\hline & Mutton & $\begin{array}{l}\text { Merino } \\
\text { Weaner }\end{array}$ & 17 & 18 & 19 & 20 & 21 & 22 \\
\hline Mutton & 1.000 & & & & & & & \\
\hline Merino Weaner & 0.949 & 1.000 & & & & & & \\
\hline 17 & 0.606 & 0.614 & 1.000 & & & & & \\
\hline 18 & 0.573 & 0.581 & 0.977 & 1.000 & & & & \\
\hline 19 & 0.559 & 0.540 & 0.921 & 0.960 & 1.000 & & & \\
\hline 20 & 0.487 & 0.439 & 0.829 & 0.870 & 0.965 & 1.000 & & \\
\hline 21 & 0.542 & 0.492 & 0.826 & 0.865 & 0.958 & 0.993 & 1.000 & \\
\hline 22 & 0.573 & 0.528 & 0.838 & 0.871 & 0.956 & 0.986 & 0.997 & 1.000 \\
\hline \multicolumn{9}{|l|}{ Summary Statistics } \\
\hline Mean & 219 & 309 & 1409 & 1264 & 1098 & 952 & 900 & 869 \\
\hline Standard Error & 4.6 & 4.5 & 14.3 & 12.2 & 9.5 & 8.4 & 8.1 & 7.6 \\
\hline Median & 191 & 286 & 1315 & 1206 & 1069 & 922 & 882 & 855 \\
\hline Standard Deviation & 100 & 98 & 312 & 267 & 208 & 184 & 178 & 167 \\
\hline Coefficient of Variation & 46 & 32 & 22 & 21 & 19 & 19 & 20 & 19 \\
\hline Minimum & 49 & 132 & 1063 & 900 & 779 & 684 & 657 & 648 \\
\hline Maximum & 467 & 598 & 2525 & 2189 & 1769 & 1588 & 1522 & 1461 \\
\hline
\end{tabular}



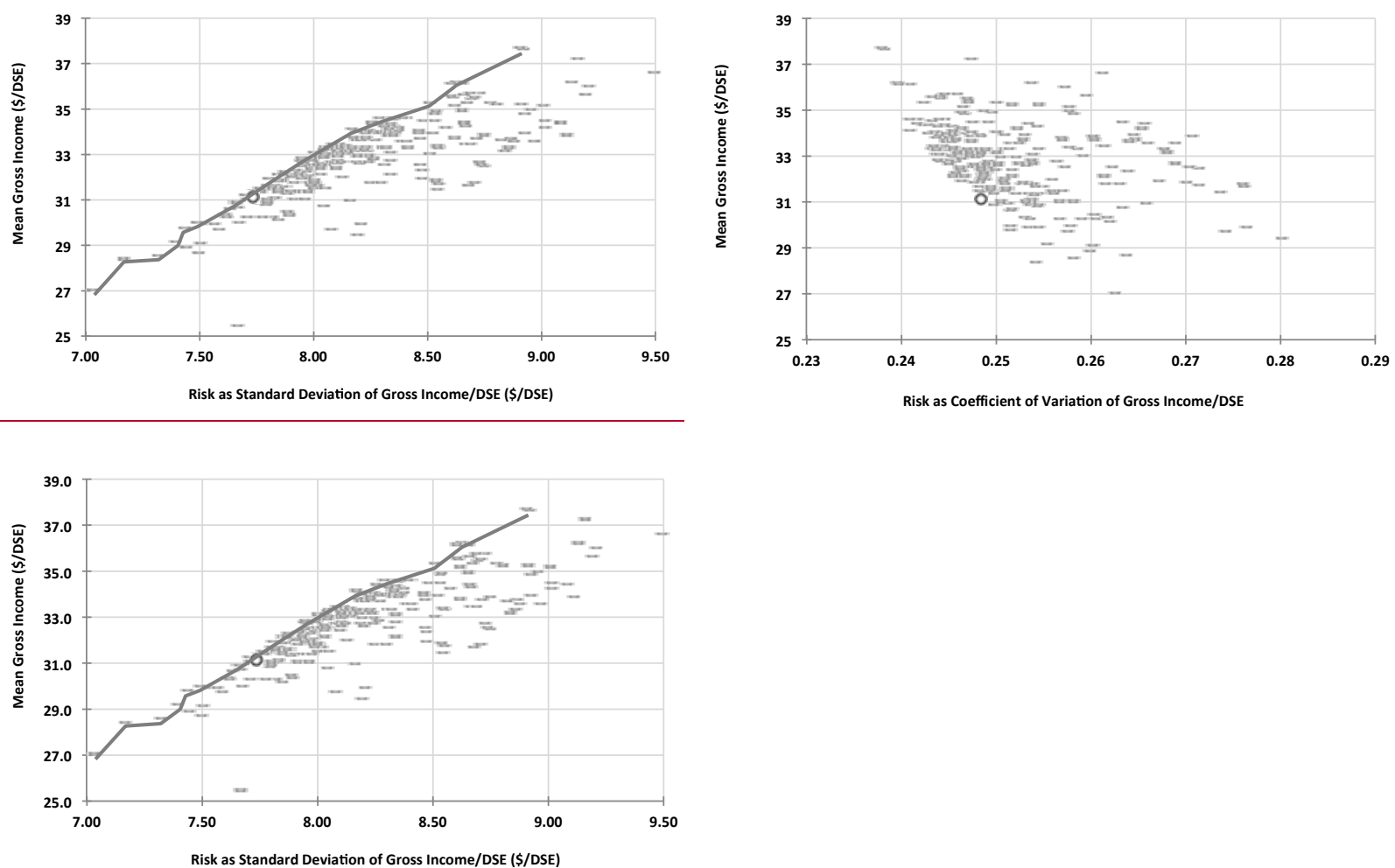

Figure 1: Risk-reward for Australia merino bloodlines, a) Absolute risk measured as Standard

Deviation of Mean Gross Income, and risk-efficiency against Mean Gross Income per DSE; b) Relative Risk measured as coefficient of variation of Mean Gross Income against Mean Gross Income per DSE.

284 of a decision makers risk aversion.

\begin{tabular}{lrrr}
\hline Descriptor & \multicolumn{3}{c}{ Degree of Risk aversion } \\
& Low (Risk neutral) & Moderate & High (Risk averse) \\
\hline Wool Fibre Diameter (microns) & 19.4 & 19.6 & 19.9 \\
Fleece Weight (kg clean/head) & 4.3 & 4.2 & 4.0 \\
Mature Body Weight (kg liveweight) & 50.2 & 51.3 & 51.9 \\
Stocking rate (head/ha) & 8.0 & 7.8 & 7.8 \\
Trading Income (\$/ha) & -3.48 & -3.50 & -3.51 \\
Wool Income (\$/ha) & 281 & 261 & 241 \\
Mean Gross Income (\$/DSE) & 34.7 & 32.1 & 29.7 \\
Standard deviation of Mean Gross Income (\$) & 8.4 & 7.9 & 7.5 \\
Coefficient of Variation of Mean Gross Income & 0.242 & 0.246 & 0.253 \\
\hline
\end{tabular}


a) Fibre Diameter
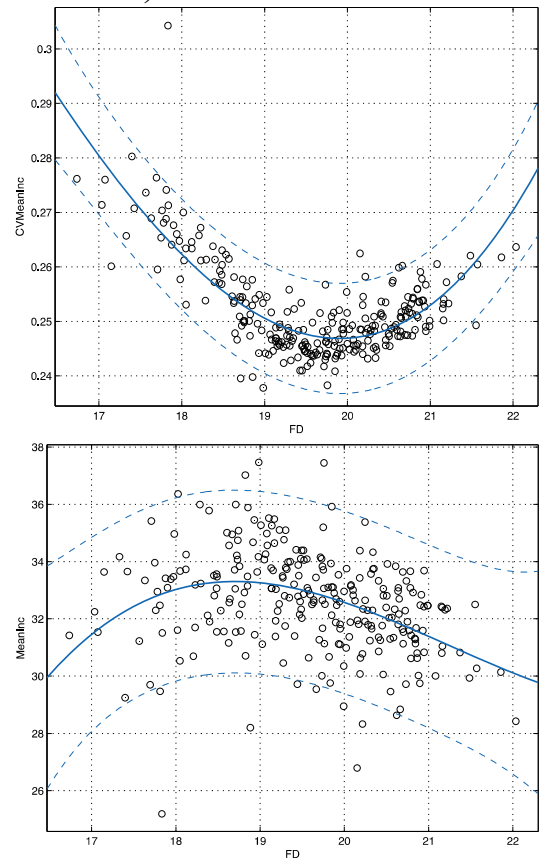

b) Fleece weight
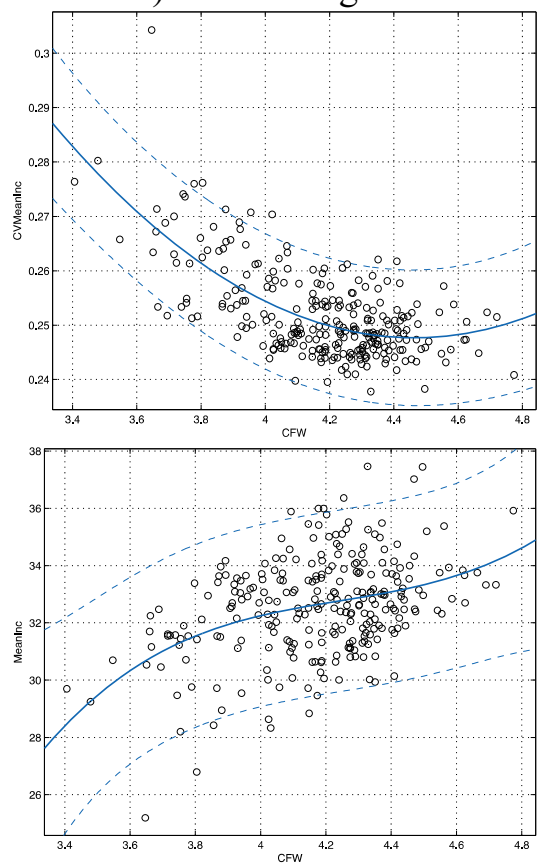

c) Body weight
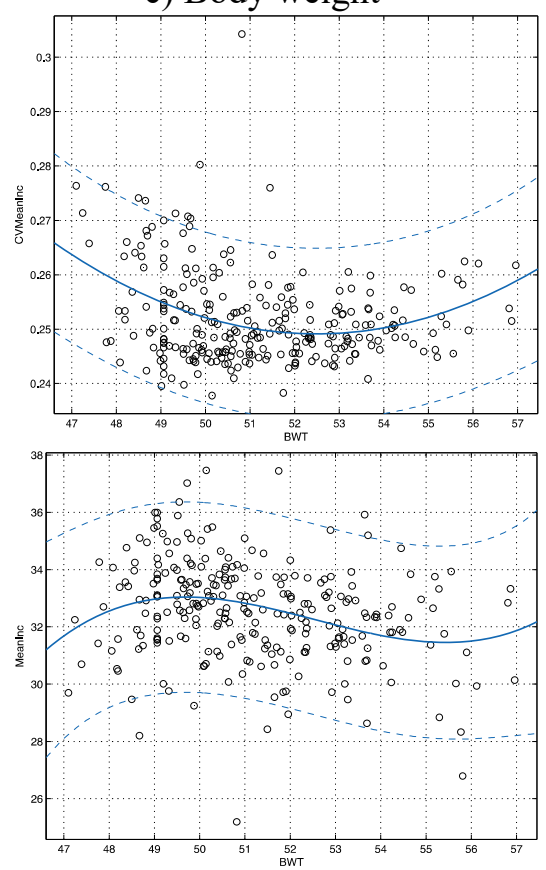

Figure 2: Relationships between bloodline a) Fibre Diameter, b) Fleece weight, and c) body weight; 